\title{
El Dr. Carlos Gianantonio
}

\author{
Dr. Carlos Gianantonio
}

E1 21 de octubre último se cumplieron 20 años del fallecimiento del Dr. Gianantonio. El tiempo que ha pasado no nos parece lejano ya que su presencia nos acompaña en todo momento y continúa siendo hoy tan vigente como en todos estos años transcurridos.

A veces llama la atención el rendir un homenaje a alguien en el día que ha fallecido, pero debe entenderse que lo que se honra a través de su muerte es su experencia de vida.

Con ese fin, la Fundación Carlos Gianantonio y el Departamento de Pediatría, realizamos, en el Hospital Italiano de Buenos Aires, un acto para evocar su vida el mismo 21 de octubre; y de esa forma recordar la enorme trascendencia que significó toda su trayectoria en la medicina. El acto contó con una nutrida concurrencia de médicos y otros profesionales. Nos alegró mucho la presencia de pediatras jóvenes, que forman parte de las ya varias generaciones que no lo conocieron; pero que en esta oportunidad pudieron absorber su grandeza y contemplar con asombro su inmenso legado. No llamó la atención esta convocatoria, porque la figura de Gianantonio fue la más relevante en la historia de la pediatría en nuestro país. Era una persona que reunía cualidades excepcionales, tanto como ser humano como por sus inmensos conocimientos; y sin duda, a través de estas invalorables virtudes logró alcanzar la sabiduría, que es el máximo atributo que una persona puede adquirir.

Fue un verdadero humanista que bregó incansablemente por mejorar la atención de los niños en nuestro país y defendió sus derechos y su dignidad, más allá de cualquier otra consideración. Produjo cambios e innovaciones notables -como la creación de la primera residencia en pediatría de la Argentina cuando solo tenía 32 años y del primer comité de ética clínica en el Hospital de Italiano, en 1985-.

A través de su accionar generó muchas contribuciones más, tan numerosas que es imposible de señalar acá, que aún hoy perduran con una inmodificable intensidad. Sus enseñanzas se transmitían a través del ejemplo de su conducta; el solo verlo cómo atendía a un niño o cómo se dirigía a los padres con palabras llenas de consuelo y esperanza, significaba un aprendizaje inigualable. Asimismo, su enorme humildad, no recuerdo que alguna vez haya hecho alarde de sus conocimientos, influía notablemente en nosotros que éramos privilegiados al ver que nuestro maestro actuaba en las antípodas de la soberbia. Esa virtud y otras muchas cualidades sólo se alcanzan con la sabiduría, y él fue aún más, un maestro de la sabiduría.

Con él no sólo aprendíamos medicina, sino que principalmente aprendíamos cómo se ejerce la medicina, que enfrenta el desafío de conjugar los conceptos científicos con el humanismo.

$\mathrm{Su}$ presencia fue esencial para muchas generaciones de pediatras, era el modelo que todos ansiábamos alcanzar.

Reitero acá lo que expresé muy sentidamente pocos meses después de su fallecimiento: "De todas las cosas que podríamos lamentar, una se impone con la mayor fuerza: haber perdido al Dr.Carlos Gianantonio. A nuestra generación correspondió el enorme privilegio de haberlo tenido y la tristeza enorme de perderlo. Nos reconforta pensar que su espiritu perdurará por siempre".

Pasados estos 20 años, nuestro querido maestro nos sigue acompañando en la ardua tarea cotidiana que depara el cuidado de los niños y sus familias.

Para los que tuvimos la enorme fortuna de estar muchos años con él, será por siempre nuestro guía y ejemplo. 